\title{
How news media (de-)legitimize national and international climate politics - A content analysis of newspaper coverage in five countries
}

\author{
Kleinen-von Königslöw, Katharina ; Post, Senja ; Schäfer, Mike S
}

\begin{abstract}
Implementing global climate change policies on the national and sub-national level requires the support of many societal actors. This support depends on the perceived legitimacy of climate policies, which can be sustained by legitimation debates in domestic news media. This article analyses legitimation statements on climate politics in newspapers of five countries for three Conferences of the Parties in 2004, 2009 and 2014 ( $\mathrm{n}=369$ legitimation statements). According to our data, it is mainly the legitimacy of international climate policies (instead of national ones) which is evaluated in national fora, and it is usually portrayed negatively. However, there is a noticeable shift in the arguments used over our 10-year period of analysis, moving from efficiency as the dominating evaluation criterion to questions of fairness in the distribution of costs and gains.
\end{abstract}

DOI: https://doi.org/10.1177/1748048518825092

Posted at the Zurich Open Repository and Archive, University of Zurich

ZORA URL: https://doi.org/10.5167/uzh-177176

Journal Article

Accepted Version

Originally published at:

Kleinen-von Königslöw, Katharina; Post, Senja; Schäfer, Mike S (2019). How news media (de-)legitimize national and international climate politics - A content analysis of newspaper coverage in five countries. International Communication Gazette, 81(6-8):518-540.

DOI: https://doi.org/10.1177/1748048518825092 
How News Media (De-)Legitimize National and International Climate Politics. A Content Analysis of Newspaper Coverage in Five Countries

Katharina Kleinen-von Königslöw

Institute for Journalism and Media Studies, University of Hamburg, Germany

Senja Post

University of Göttingen, Germany

Mike S. Schäfer

Department of Communication and Media Research, University of Zurich, Switzerland

Corresponding author: Katharina Kleinen-von Königslöw, University of Hamburg, Allende-

Platz 1, 20146 Hamburg, Germany, katharina.kleinen@uni-hamburg.de

Declaration of Conflicting Interests The author(s) declared no potential conflicts of interest with respect to the research, authorship, and/or publication of this article.

Funding This work was supported by the Swiss National Science Foundation (Schweizerischer Nationalfonds zur Förderung der wissenschaftlichen Forschung (SNSF)) under [Grant number 100018-153651]. 
How News Media (De-)Legitimize National and International Climate Politics. A Content Analysis of Newspaper Coverage in Five Countries

Abstract

Implementing global climate change policies on the national and sub-national level requires the support of many societal actors. This support depends on the perceived legitimacy of climate policies, which can be sustained by legitimation debates in domestic news media. The following article analyzes legitimation statements on climate politics in newspapers of five countries for three Conferences of the Parties in 2004, 2009, and 2014 ( $n=369$ legitimation statements). According to our data, it is mainly the legitimacy of international climate policies (instead of national ones) which is evaluated in national fora, and it is usually portrayed negatively. However, there is a noticeable shift in the arguments used over our 10-year period of analysis, moving from efficiency as the dominating evaluation criterion to questions of fairness in the distribution of costs and gains.

Keywords: Legitimation debates, climate change politics, comparative content analysis, Conference of the Parties, global governance, transnational public sphere 


\section{Introduction}

Political solutions to address climate change are sought to a considerable degree on the global level. This is particularly relevant for mitigating climate change, i.e., for efforts to reduce greenhouse gas emissions, which represent the most important avenue of current climate politics. The Paris agreement negotiated at the Conference of the Parties in 2015 represents a major success of this form of response to global warming. In its aftermath, however, the pitfalls and problems of climate politics negotiated at the global level became all too apparent when the U.S. president Donald Trump announced the U.S.' withdrawal from the agreement in 2017: The success of these international efforts clearly depends on the support they receive on the national level. They have to be ratified and implemented in national contexts (Giddens, 2011). This is particularly important as, unlike „hard“ EU regulations, UNFCCC agreements are less binding and allow for more interpretation and variation (Zürn, 2004). Without strict legal bindings or effective enforcement proceedings in place, national compliance with international norms and regulations strongly depends on their perceived legitimacy: 'the extent to which a rule is recognizable as a legitimate obligation affects the extent to which it is obeyed' (Franck, 1990). In other words, even if U.S. president Donald Trump had not openly renounced the Paris agreement, its implementation in the U.S. would have been severely handicapped by the fact that its current political leadership, and a substantial part of its population, is not convinced of its legitimacy.

To understand the potential impact of international climate politics, it is therefore essential to look at how they become subject to national debates in which different stakeholders compete to make their positions and policy preferences heard with the aim of influencing how international agreements are debated in domestic media and, indirectly, their chances of success on the national and international level.

News media are the most important arena - the 'master forum' (Ferree et al., 2002: 9) - of such public debates. There, society's problems are defined and different stakeholders' 
arguments are presented to citizens and decision-makers. The media and journalists take active parts in such media debates, partly by selecting and presenting others' views and preferences in certain ways, partly by voicing their own.

A large, and still rising, number of studies have analyzed media portrayals of climate change (for overviews see Nisbet et al., 2018 or Schäfer and Schlichting, 2014). But while they have dealt with numerous facets of such media portrayals, such as issue attention (e.g., Schmidt et al., 2013; Schäfer et al., 2014), framing (e.g., Shehata and Hopmann, 2012; O’Neill et al., 2015), attributions of the responsibilities for climate change (Post et al., 2018) or the representation of the science of climate change (e.g., Boykoff and Boykoff, 2004; Ladle et al., 2005), only few of them have focused on climate politics and, particularly, its legitimation in media debates (e.g., Karlsson-Vinkhuyzen et al., 2013). This is a surprising desideratum given the importance of the issue. We approach this problem by analyzing the legitimation of climate politics in the newspaper coverage of different countries. We compare patterns in legitimation debates surrounding the Conferences of the Parties (COPs) in 2004, 2009 and 2014 in five countries that are affected by climate change and climate politics to different degrees, and also outline differences over time.

The conceptual framework of the study, its research questions and hypotheses will be presented in section 2. Section 3 outlines its data and methods. Section 4 presents the results and section 5 summarizes and discusses them.

\section{Theoretical Framework: Legitimating Climate Politics in the Media}

\subsection{Media Debates of Climate Change, Climate Politics, and the COPs}

News media are essential for democratic societies. In an idealized view, they provide a public forum for political debate and thus an overview for citizens of relevant political issues and the different political positions concerning those (Ferree et al., 2002). In recent years, climate 
change has increasingly been discussed in media around the world, though there remain substantial national differences in the amount of media attention (Schmidt et al., 2013, Broadbent et al., 2016): Climate change as a topic is much stronger in industrialized countries, though the issues has gained more attention in emerging economies such as India and Brazil lately.

International events such as the COPs have been particularly impactful in bringing the issue of climate change to the attention of the media and, thus, of the citizens. During COPs, media coverage about climate change peaks annually (Schmidt et al., 2013, Schäfer et al. 2014), and the conferences themselves are crucial deliberative opportunities for stakeholders in climate change politics (Lück et al., 2018). They also have an impact on citizens' attention towards climate change, even though their effects on citizens attitudes remain debated (Brüggemann et al., 2017). The question remains whether this coverage has the potential to increase the political legitimacy of climate change politics.

The legitimacy of a political system or regime denotes its rightfulness and acceptance. Research on the legitimacy of specific political regimes either addresses the so-called objective legitimacy, which is assessed based on a-priori defined normative criteria derived from democratic theory. Or it explores subjective legitimacy, tapping into the societal acceptance of political regimes by analyzing the legitimacy evaluations of the people affected by them and the underlying evaluation criteria (Fuchs, 2011). Subjective legitimacy relates to the regime as a whole. It can be understood as a form of 'diffuse support' (Easton, 1965), which in turn is expected to increase the acceptance of and support for specific regulations and laws, hence, effective government (Scharpf, 2003).

From a normative-objective perspective, most international political regimes have a democratic deficit compared to the democratic nation states that transferred (some of) their power to them (Zürn, 2004). In climate politics, the societal acceptance (i.e., the subjective legitimacy) of the involved international institutions and their regulations is particularly 
important for a number of reasons (adapted from Zürn, 2004): Firstly, the eventual addressees of climate regulations are often not national governments but societal actors such as the citizens themselves or private companies. After all, they are the ones needed to adapt more climate-friendly habits or develop more climate-friendly products and technologies. Secondly, this regulation needs to be coordinated not only on a national level, but also beyond national borders. Thirdly, climate politics is concerned with highly complex problems that are not easily understandable for many citizens (Moser, 2010; Schäfer, 2015). Consequently, 'unlike most other international regimes, [climate politics'] failure is even possible if the signatory governments have the full intention to reduce CO2 emissions.' (Zürn, 2004: 269). It requires extensive administrative and technological resources to implement the international regulations on the (sub)national level, and notwithstanding the amount of resources allocated, all efforts may fail simply because citizens refuse to change their daily habits or companies refuse to develop the required products because they do not perceive the policies as legitimate.

Given their lack of objective legitimacy, international political regimes depend more strongly than national political actors on subjective legitimacy which 'is established and challenged through a rational discourse' (Steffek, 2003: 271). The role of news media in providing a forum of debate is particularly important given the abstract nature of the underlying political issue. Without media debates, climate policy has little chance to gain subjective legitimacy, and thus potentially support, among ordinary citizens who are needed to adjust their lifestyles or develop their own ideas on how to contribute towards climate saving political goals.

According to Hurrelmann et al. (2009), such legitimation debates consist of statements addressing the legitimacy of political objects (= legitimation statements). Following Habermas' understanding of discourse as an exchange of intersubjective 'speech acts' (Habermas, 2003), legitimation discourse and thus the subjective legitimacy ascribed to 
certain political regimes can be ascertained by looking for these legitimation statements in news media. Legitimation statements are statements in which the legitimacy of political objects (such as the political system, political institutions, political actors or policies) is assessed based on normative ideals (see also Hurrelmann et al., 2009).

Our first research question, therefore, is: To what degree are national and international political climate regimes the objects of legitimation statements in national media?

As the awareness of climate change in general, and of climate politics as the most important way of addressing it has increased in most countries in recent years (Schmidt et al., 2013), we assume that the increase in climate change coverage is mirrored by an increase in legitimation statements in the media as well (H1).

Our second research question asks: What patterns of legitimation statements are found in media debates? According to Hurrelmann et al. (2009), legitimation statements typically include a source (the author of the statement such as a journalist, political actor or citizen), a legitimation object (such as the IPCC), its evaluation (whether is the object legitimized or delegitimized), and the arguments on which the evaluation is based (normative legitimation criteria).

As climate change is generally perceived as a problem of global scale requiring a globally coordinated response, we expect that legitimation statements are more likely to focus on this international level of climate politics $(\mathrm{H} 2 \mathrm{a})$. As more and more countries have ratified the Kyoto protocol (or now the Paris agreement), we further expect that climate politics has shifted from establishing an international regime to the implementation of its decisions on the national and subnational level, leading to an increased scrutiny of the national level (H2b). Similarly, we assume that international actors have a greater need to legitimize their existence and actions than national actors, given the lack of objective legitimacy. Based on this, we expect that, more often than national actors, international actors appear as sources of 
legitimation statements (H3a). However, with the domestication of climate politics, national actors should increasingly become involved in the discussion of their legitimacy (H3b). Regarding the evaluation of climate politics in legitimation statements, we assume that international climate politics are more often de-legitimized than national politics $(\mathrm{H} 4 \mathrm{a})$ - as they lack objective legitimacy and cannot effectively defend themselves against attacks in national arenas. Given the generally growing acceptance of climate change as a global problem, however, we expect that both national and international climate regimes are increasingly legitimized (and decreasingly delegitimized) in public discourse (H4b).

In legitimizing or delegitimizing political regimes, speakers may make use of a wide range of arguments. Previous studies have identified a number of potential legitimation arguments or criteria for political governance on different levels of government (Nullmeier et al., 2010) and for specific policy fields (Schneider et al., 2010).

These legitimation criteria can relate either to the input or to the output of the political process (Scharpf, 1999): Input-based arguments concern the question of how political decisions are reached. An example would be whether all people affected by policies are represented in the decision-making process (representation), or whether they actually have a chance to participate and contribute actively (participation). As the international level of climate politics is currently dominating the media coverage, questions of representation and participation might be discussed both with respect to the respective nation - whether one's own nation and its interests were adequately represented in the international arena - and to civil society and citizens (for a similar argument relating to global energy governance, see Karlsson-Vinkhuyzen, 2015). Even though NGOs representing citizens' interests are relevant players in international policy negotiations (Kuyper et al., 2018), this does not necessarily mean that their participation is visible in domestic media debates.

Other arguments regarding the input in the climate policy process might relate to the question whether an exchange of arguments occurs (deliberation), whether the process is 
transparent (transparency), its participants are credible (credibility) and possess the required expertise and experience or at least base the decision on expert knowledge (expertise; table 1).The latter argument is of particular importance in the case of climate politics given the scientific complexity (and at times uncertainty) relating to both the issue itself and the proposed policy measures.

Output-based arguments relate to the results of the political decision process, their nature and consequences (Scharpf, 1999: 682). For example, arguments could refer to the effectiveness and efficiency of the policy output. In the field of climate politics, effectiveness of proposed policies is a particularly relevant argument, given the fact that proposed measures often depend on prolonged ratification processes and their impact on climate change can be difficult to assess.

Output legitimacy might also relate to the question of whether climate policy observes human rights, empowers people in climate change politics, or whether it achieves a fair distribution of costs and gains or enhances the common good (fairness/common good). In particular, the question of the fairness has received much attention in public debate of international climate regimes, as countries strongly differ in how strongly they have contributed historically towards climate change, and how affected they are by climate change itself or by the proposed measures (Post et al., 2018).

As experimental studies have shown that public support of international environmental governance depends more on output than on input criteria of legitimacy (Bernauer et al., 2016), we hypothesize that output criteria of legitimacy also play a greater role in national debates of climate change policy $(\mathrm{H} 5 \mathrm{a})$.

Hurrelmann et al. also differentiate between arguments relating to 'essential features of democracy' (Hurrelmann et al., 2009: 499) ${ }^{\mathrm{i}}$, such as representation or the protection of human rights, and those that are not essential to democracy from a normative perspective, such as effectiveness or expertise. It could be argued that in the field of climate politics, these non- 
essential legitimacy arguments may in fact be more important given the scientific and political complexity of the issue. In addition, Scharpf (2000) has argued that we are currently witnessing a general 'change in the normative formations of the democratic nation-state's legitimacy' from essential to non-essential criteria, in particular towards effectiveness. We therefore assume that such a shift towards non-essential criteria is also observable in the legitimation of climate politics (H5b).

- Table 1 about here -

In addition to these hypotheses, we will explore in our third research question whether these legitimacy patterns differ between countries. On a general level, news coverage of international events such as the COPs tends to be 'domesticated', i.e., adapted to national political interests and national political culture (Nossek and Kunelius, 2012). In the case of legitimacy debates, this is also likely to be the case: When journalists and political actors argue for or against the legitimacy of a political regime, they will use arguments that resonate with their respective audiences (Hurrelmann et al. 2012). In their reporting, journalists might give preference to legitimation statements by international actors that align with the national political culture.

In the specific case of climate change policy, the interest in international climate regimes as legitimation objects, but also the sources of legitimation statements might depend on a nation's general involvement in international regimes (for example as part of the EU, NATO or the UN), i.e., its 'degree of political internationalization' (Hurrelmann et al., 2009: 492). Legitimacy evaluations as well as legitimation arguments might depend on a country's affectedness by climate change effects: In more affected countries, for example, the effectiveness of climate policies might play a greater role in evaluating climate politics. By contrast, fairness might be more important for countries strongly affected by secondary effects 
of climate change or for emerging economies who feel less responsible for causing climate change in the first place. In a similar manner, countries that are not involved in international regimes are more likely to question the legitimacy of the input of a decision-making process in which they find themselves not represented and unable to participate.

\section{Data and Methods}

\subsection{Identification of relevant articles}

This study is based on a content analysis of coverage of the Conferences of the Parties (COPs) in 2004 (Buenos Aires), 2009 (Copenhagen) and 2014 (Lima) in opinion leading national newspapers in five countries - Australia, Brazil, Germany, India and the United States of America. We chose democratic countries in which the freedom of the press was by and large guaranteed throughout the period of investigation (Freedom House, 2012; cf. Wessler et al., 2016), and which are vulnerable to climate change to different degrees (e.g., Harmeling, 2009). In addition, we included both industrialized Western as well as emerging economies (Schäfer et al., 2014).

For each country, we analyzed one liberal-leaning and one conservative-leaning newspaper. ${ }^{\text {ii }}$ We sought to identify all the newspaper articles on climate change politics that were published from one week before until one week after each COP. ${ }^{\mathrm{iii}}$ In a first step, we drew all newspaper articles from Lexis Nexis and Factiva ${ }^{\mathrm{iv}}$ that contained the terms 'climate', or 'global warming'. In a second step, we developed a complex search term in English, German, and Portuguese based on which we could differentiate the articles on climate change politics from articles on other subjects. To evaluate our search term, we calculated accuracy (the share of articles that was classified correctly as relevant or irrelevant by the search filter), precision (the degree to which articles that were identified as relevant for climate politics were correctly identified), recall (the ratio of articles coded as relevant to all relevant articles in the sample) and F-values (the harmonic mean of precision and recall (Scharkow 2011, table 
2) based on the comparison of our search results with a manual classification of about 100 articles. For all these measures, we obtained values well above .80 for all languages, which indicates that our search filters were well reliable.

- Table 2 about here -

Through this procedure, we identified 316 articles in the Australian and 228 in the Sydney Morning Herald, 169 in the Estado do Sao Paulo and 167 in the Folha de Sao Paulo, 257 in the Frankfurter Allgemeine Zeitung and 316 in the Süddeutsche Zeitung, 137 in the Hindu and 127 in the Times of India, 113 in the New York Times and 108 in the Washington Post. For our manual content analysis, we randomly selected samples of 20 articles per newspaper and year. In some years, some newspapers published less than 20 articles. In this case, we analyzed all articles.

\subsection{Coding procedure}

Four coders identified and coded the legitimization statements. Following Hurrelmann et al. (2009), we defined legitimation statements as evaluative references to political objects or processes that are legitimized or delegitimized by a speaker based on specific arguments. As political objects of legitimation, we captured domestic national political actors or processes, national political actors or processes in countries abroad as well as supranational actors, organizations, institutions, regimes or processes. As speakers, we captured social actors from all domains, e.g., civil society (NGOs, activists), national politics, international politics, economics, science and academia, journalists and others (such as members of churches, artists etc.). In addition, we captured their countries of origin. As arguments for (de-)legitimation, we captured references to the input and the output of climate change policies, as well as arguments essential and non-essential to democracies. As we look at legitimation statements 
in newspapers, speakers of legitimation statements can be either actors cited by journalists (directly or indirectly) or the journalists themselves, if they express a clear evaluation of a political object (this is more likely to occur in comments and editorials, but can also occur in other journalistic genres).

Coders were trained to identify legitimation statements based on the three elements speaker, object of legitimation, and argument. Reliability tests of the arguments of legitimation are based on all the statements that were identified by at least one of the four coders or the principle investigator $(n=52)$. For each statement that coders identified, they assigned positive codes for legitimizing and negative codes for delegitimizing arguments. For each case in which a coder did not identify a statement that others identified a zero was assigned. Based on this dataset, we calculated Krippendorff's alpha $=.80$ indicating that reliability of identifying relevant statements and coding the correct evaluative arguments was very satisfactory (due to reliability concerns, we combined the two legitimation criteria fairness and common good in one category). Coders' test classifications of speakers, their countries of origin as well as the objects of legitimation were based on 81 cases. As the catalogue of objects of legitimation was aggregated from the catalogue of speakers, we did not calculate separate tests for the objects of legitimation. Both the coding of the speakers' function in a respective social domain (Krippendorff's alpha $=.84$ ) as well as their countries of origin (Krippendorff's alpha $=.93$ ) were highly reliable.

\section{Results}

\subsection{Prevalence of legitimation statements in the media}

Our first research question concerns the prevalence of legitimation statements concerning climate politics in domestic media. The analysis shows that matters of legitimation play a considerable role in media coverage about Conferences of the Parties, with coders identifying 343 legitimation statements in the 502 articles of our sample: Overall, approximately 40 
percent of all articles on climate politics also address questions of legitimacy. There is, however, no clear evidence for an increase of legitimation statements over time (H1a falsified): In most countries, legitimacy was debated relatively often during COP 2004 (42 percent), but this did not intensify, or decline, for COP 2009. In 2014, the share of articles on climate politics touching upon legitimacy questions reaches similar levels as in 2004.

Furthermore, the analyzed countries differ clearly in the importance that their respective media give to legitimation statements. Striking differences exist between the developed, industrialized countries Australia, Germany and the US on the one side, where legitimation statements are comparatively common and the legitimacy of climate change policies is debated very often, and emerging economies Brazil and India on the other side, where the legitimacy of climate regimes - as well as the COPs themselves - are debated less frequently. This mirrors findings on the different degrees of media attention to climate issues in ‘Western’ vis-à-vis non-'Western' countries (Schmidt et al., 2013) as well as qualitative studies on the different frames of climate politics in these countries (Billett, 2010; Schmidt and Schäfer, 2015).

- Table 3 about here -

\subsection{Patterns of legitimation statements}

For our second research question, we look in more detail at the patterns of legitimation statements. Regarding the objects of legitimation, the bulk of legitimation statements addresses the (de-)legitimacy of international climate politics, its institutions or regimes (63 percent). For example, representatives of the US administration explain their refusal to sign the international agreement by 'challenging the scientific assumptions underlying the Kyoto protocol' (Rother, New York Times, December 19 $\left.{ }^{\text {th }}, 2004\right)$. By contrast, in Germany the COP 2004 was praised as a 'historical moment' as the Kyoto protocol was finally entering into 
force and first results could already be seen (Kreye, Süddeutsche Zeitung, December $18^{\text {th }}$, 2004).

About a quarter of the statements are directed at domestic climate regimes of the respective country, whereas the national climate politics of other individual countries are only discussed in 10 percent of the statements (confirming $\mathrm{H} 2 \mathrm{a}$ ). In our sample, the focus on international climate politics is strongest in 2009, but drops again in 2014. In other words, there is no continuous increase of the relevance of the national level of climate politics and policies (rejecting $\mathrm{H} 2 \mathrm{~b})$.

However, we can observe country differences in our sample. In the US, legitimation statements have shifted from a national to an international focus over time (Konieczny, 2014). By contrast, in Australia and Brazil, the attention became increasingly directed towards national climate politics. The role of national climate regimes has remained stable in Germany and India, though at different levels: In Germany, the role of national climate politics is comparatively strong (40 percent) whereas in India, it is minimal (six percent). This is in line with Billett's (2010) findings that Indian media coverage on climate change focused mostly on the responsibility of developed countries, and also in line with the results of a comparative analysis of attributions of responsibility based on the same data set as this study (Post et al., 2018). It deviates, however, from a comparative study of climate change coverage by Broadbent et al. (2016), who showed that Indian media frame climate change mostly by looking at domestic ecological impacts, whereas German media coverage focuses on climate change's global impact. This indicates a problematic gap between how climate change is defined as a problem in media debates, and on which level political solutions for this problem are discussed.

- Table 4 about here - 
According to our data, both political actors and journalists account for about 30 percent of the legitimation statements. Scientific experts (15 percent) and NGOs or climate activists (11 percent) also often evaluate the legitimacy of climate change politics, followed by economic actors (eight percent). In the proceding analysis, we will not focus on the type of speakers, but on their origin: Is the debate about the legitimacy of climate change politics in domestic media dominated by domestic speakers or those from the international arena?

Notwithstanding international institutions' predominance in the realm of climate politics, international actors are not the main sources of legitimation statements in domestic media (rejecting hypothesis 3a). Domestic speakers dominate legitimacy debates overall (57 percent), and their share has increased over time (from 49 to 63 percent, confirming H3b).

This overall finding again masks variation between the countries, however. In the developing countries Brazil and India, domestic speakers are second to speakers from other countries or speakers from international climate politics institutions (Schäfer et al. 2018). Notably, speakers from international organizations or institutions play a comparatively prominent role in India (Billett, 2010; Schäfer et al., 2014). This is surprising given Lück et al.'s (2018) finding that at several COPs there was a comparatively close contact between the Indian press corps and its delegation. Apparently, this close contact has not made national speakers the preferred sources for statements on the legitimacy of climate politics. By contrast, speakers from other countries play a comparatively prominent role in Brazil. And the trend of a domestication of legitimation statements has a notable exception: It is not found in the US, where domestic speakers are increasingly replaced by speakers from other countries or international organizations or institutions (Konieczy, 2014).

Most of the speakers cited from other countries in legitimation statements are from the US (29 percent of 79 legitimation speakers from abroad in news coverage in Australia, Brazil, Germany, India and the UK), Russia (10 percent), China (9 percent), Germany ( 9 percent), the UK (6 percent) or India (6 percent). Though the Brazilian COP delegation has the strongest 
outreach strategy to international journalists (Lück et al. 2018), this strategy has not resulted in Brazil being heard in the legitimacy debates of other countries (only a single legitimation statement from a Brazilian speaker was found outside Brazilian media).

- Table 5 about here -

Overall, legitimation statements in the realm of climate politics mostly serve to delegitimize, in line with findings from political communication research on other policy fields (Schneider et al., 2010) or on other international institutions (Gronau et al., 2009) and with the systemic preference of journalism for negativity and criticism (Lengauer et al., 2012). As assumed in hypothesis $4 \mathrm{a}$, the share of critical statements is higher for international climate politics (76 percent) than for domestic objects ( 25 percent). Furthermore, signs of an increasingly more positive evaluation are weak at best; there is only a marginal increase in the share of positive evaluations between 2004 and 2014. In the case of domestic climate politics, their support increased between 2004 and 2009, but then drops again (H4b rejected).

No clear pattern emerges when looking at the evaluation of climate regimes in the different countries: In both Germany and Brazil, support for domestic climate regimes is comparatively strong (39 and 43 percent are positive evaluations, respectively). In Germany, this is also mirrored by a comparatively strong support for international climate regimes (44 percent positive). However, in both emerging economies, i.e., in Brazil and in India, the legitimacy of international regimes is strongly questioned (with only 10 and 13 percent positive evaluations) on the rare occasions that it is being debated (see 4.1, and also Billett, 2010; Schmidt and Schäfer, 2015).

- Table 6 about here - 
The described (de)legitimation statements rely mostly on a small selection of arguments: For both national and international climate regimes, efficiency/effectiveness arguments are mostly used to evaluate their legitimacy (share of 67 and 54 percent respectively). For example the Kyoto protocol is criticized because the 'pledged emissions cuts would almost certainly allow for warming far beyond 2 degrees Celsius, the threshold beyond which scientists say global warming could be disastrous.' (n.a., The Washington Post, December $\left.20^{\text {th }}, 2009\right)$. Together with fairness/common good and human rights/empowerment arguments, the share of legitimacy evaluations based on the output of the political process makes up a large majority of all (de)legitimation arguments. It accounts for 78 percent (national) and 70 percent (international) of statements (de-)legitimizing climate regimes regimes (H5a confirmed).

In the case of national regimes, this dominance of output-based criteria becomes even stronger over time, as efficiency, a non-essential criterion for democratic regimes, and human rights/empowerment, a criterion essential for democratic regimes, gain prominence. Around the COP 2014, 17 percent of all evaluations of national regimes refer to the empowerment of people or the protection of individual human rights and liberties. This comes at the expense of the input criterion expertise/experience, whose share dropped from 13 to three percent. Overall, there is no increase in the relevance of non-essential democratic criteria for evaluating national climate regimes (75 percent in 2004, 79 percent in 2009 and 77 percent in 2014).

With regard to the evaluation of the legitimacy of international climate regimes, inputbased criteria such as representation, participation and transparency have gained importance between 2004 and 2014 (from 21 percent to 33 percent): In particular, the 2014 COP in Lima was judged harshly on input criteria, e.g. when journalists wrote that 'COP 20 will be remembered for bad process, non-transparency \& non-inclusiveness.' (n.a., Times of India, 
December $\left.14^{\text {th }}, 2014\right)$. This criticism was not limited to the news coverage in emerging economies, the Australian also criticized the COP for 'not allowing the views of the countries to be heard' (n.a., The Australian, December $\left.10^{\text {th }}, 2014\right)$. At the same time, efficiency lost in prominence (dropping from 64 to 47 percent). The overall share of arguments from the core of democratic theory thus increases in the debate of the legitimacy of international climate regimes (to 33 percent in 2014). Hence, hypothesis $5 \mathrm{~b}$ is not confirmed for international regimes.

Again, country differences are visible, even though the small number of cases calls for cautious interpretation. Most striking is the overwhelming dominance of efficiency as an argument in German legitimation discourse of national climate politics (89 percent of all arguments). Looking at the statements on international climate regimes, the case of India stands out, where input-based as well as democratic criteria dominate: In India, international climate regimes are mostly evaluated based on whether they allow the participation of all affected countries, and whether the proceedings are transparent (Billett, 2010). Their efficiency, by contrast, is contested much less than in other countries. In the German debate of international climate politics it is also notable that arguments regarding fairness in the distribution of costs and risks are used comparatively often (22 percent), reflecting a strategic stance that the differentiation between industrialized countries and developing nations in their responsibility for limiting climate change is 'outdated' ('Die Industriestaaten halten diese Trennung für überholt.' Mihm, Frankfurter Allgemeine Zeitung, December 15 $\left.5^{\text {th }}, 2014\right)$. Yet, the developing countries Brazil and India rarely refer to this argument (five and eleven percent, respectively).

- $\quad$ Table 7 and table 8 about here - 


\section{Discussion and Conclusion}

Domestic debates about the legitimacy of international and global policy regimes are important, as these endeavors often have an inherent democratic deficit while still depending on national implementation. This is particularly true for politics addressing climate change, a global problem transgressing national boundaries in its causes and effects for which solutions are sought mostly via international political agreements.

National media debates play an important role in the (de)legitimation of such international politics. Given this importance of media debates about international climate politics, it is surprising that very few studies have focused on them so far. We tried to remedy this, and were able to show that analyzing legitimation debates in the media is a worthwhile subject: When, in the context of the COPs, climate politics is covered in the media of different countries, the question of their legitimacy is touched upon regularly in the industrialized countries under study, though less often in the emerging economies Brazil and India.

Perhaps not surprising given our focus on three COPs, most of the legitimation discourse focuses on international climate politics, policies and institutions. These international actors and organizations, however, rarely get the chance to defend (or challenge) their own legitimacy. The debate is dominated by domestic speakers, or in the case of emerging economies and increasingly of the US, by speakers from other individual countries. Overall, these speakers are not impressed with climate regimes: They strongly question the legitimacy of international climate politics and, to a slightly lesser degree, of national climate politics. Their main argument relates to the perceived inefficiency of international and national climate regimes.

However, it could be argued that because climate change politics are a new policy field, the fact that its legitimacy is already being regularly discussed (in the industrialized nations) represents a step in the right direction. This is particularly true as climate change policy is often evaluated negatively because of its lack of effectiveness: After all, these negative 
evaluations do not negate the overall need for climate change policy, but can also be interpreted as calls for more effective climate governance.

The aforementioned pattern did not change much during the ten years of our analysis. There is a slight trend towards an even further domestication of legitimation debates, as domestic speakers increased their share of all voices at the cost of speakers from other countries or from international institutions. The most interesting shifts occurred with respect to the arguments used to evaluate climate politics: Though efficiency remains the most important argument, it loses some of its prevalence with regard to international climate politics. This may be a result of the (slow) political progress achieved. As more and more countries ratified the climate agreements, the discussion no longer concentrated on the question of whether they will enter into force or not, but moved on to concrete conflicts caused by their implementation, in particular with regard to a fair distribution of costs and gains.

From a normative point of view, the conclusions we can draw from our empirical assessment of the discursive legitimation of climate politics are rather disappointing. Though international climate politics have the greater need to be the focus of legitimation debates due to their lack of objective legitimacy, they are mostly reduced to a passive role, with little chance to improve the overall negative evaluation of their legitimacy (cf. Konieczny, 2014). As in the case of other international institutions, such as the EU, the preferred strategy of national political actors appears to be to 'shift blame' to the international level to increase their own standing (Hobolt and Tilley, 2014; Gerhards et al., 2009). In addition, most of the legitimation statements are based on arguments non-essential to democratic regimes, such as efficiency and fairness. Hence, it is doubtful that the observed debates can enhance the general democratic awareness of citizens or contribute to improving the overall acceptance of climate politics - on the international or national level. 
This may not have stopped the successful ratification of the Paris agreement in 2016, but it may hinder its successful implementation in the future when local, regional and national conflicts regarding concrete climate policies arise. It thus seems regrettable that, with the notable exception of Germany, national debates mostly missed out on the opportunity to bring national climate politics into the discussion of the COPs. This problematic disconnect between the international and national level of climate politics seems strongest in the emerging economies - particularly in India, where international climate politics are depicted as a distant, negative affair, a playing field for international actors (cf. Billett, 2010; Schäfer et al., 2014), in which India does not have much of a role (or is refused a role), but whose decisions also seem inconsequential to the country. This does not bode well for the acceptance of local climate politics in support of the Paris agreement by the Indian population.

As all studies, this study has a number of limitations as well: Climate politics is a comparatively young policy field, which has come under public scrutiny only in recent years. To sample a sufficient amount of articles on climate politics for all countries and years of analysis, we focused on newspaper coverage before, during and after the COPs. Selecting such an international and decidedly political event may have influenced our results in several ways, and may be partly responsible for the strong(er) attention to international over national climate politics or the focus on output-related, non-democratic arguments for (the perceived lack of) legitimacy.

Despite this sampling strategy, case numbers are rather low, in particular for our first point of observation (the COP of 2004), and for the national level of climate politics. As a result, we had to forgo a differentiation between legitimation debates in newspapers of different political leanings and not all of our results achieve statistical significance. However, as in some cases we have analyzed a high share of or even all relevant articles, we are confident that we can still draw valid conclusions. 
It was the aim of our country selection to reflect possible differences in the public legitimation of climate politics between industrialized countries and emerging economies with varying levels of responsibility for and affectedness by climate change. Some of the differences between countries we identified in our study, however, may not be specific to the debate of climate politics but grounded in the more general differences in journalistic and political cultures of the respective countries. For example, both Indian and Brazilian journalists have a more collaborative understanding of journalism, in which journalists are more willing to support government policy, to convey a positive image of political leaders and to support the national development (WJS, 2017). This might make them less likely to question political legitimacy (or cite people questioning political legitimacy) in general, explaining the overall low share of legitimation statements in these countries, but not the negative tone of these rare evaluations, or the comparatively low level of media attention to climate change in general (Schmidt et al., 2013, Broadbent et al., 2016).

As countries may differ in their understanding of the role of citizens (Dalton and Welzel, 2015), of what is considered fairness or the common good (Ylä-Anttila and Luhtakallio, 2017), and how trust in science - and in political decisions based on science - is generated (i.e., the 'civic epistemologies', Jasanoff, 2007), these differences could affect the prevalence of certain legitimation arguments, independent of the policy field under discussion.

In other words, India's stronger focus on input criteria, i.e., on participation as a criterion, might either be the result of a concrete desire to strengthen the country's role in international climate governance or of a political culture emphasizing participation rights in general. Unfortunately, we currently lack both comparative studies of political cultures and of legitimation debates focusing on other policy fields to be able to disentangle this. For international speakers aiming to increase the support for climate politics in specific countries, this knowledge of specific political cultures would be valuable to ensure that they are using the legitimation arguments more likely to resonate with their audiences. 
On a more general level, journalists and other speakers aiming to foster support of and thus compliance with international and national climate policies would be well advised to use a broader range of arguments to justify the climate regime, e.g., climate policies need not only be implemented because they are the only effective way of addressing the problem of climate change, but because they are fair and we all benefit from them. Such a broader range of arguments is more likely to resonate with a wide range of allies and opponents, thus increasing the likelihood of support (Ylä-Anttila and Luhtakallio, 2017). This aligns well with Giddens' (2011) assessment that climate change policy can only succeed when it is integrated within wider political programs that address other problems such as social justice or economic competitiveness.

As the relevance of climate politics, and especially national climate politics, continues to increase, future studies should exploit this growing public attention by comparing our findings with other political events, or phases of routine coverage, focusing particularly on the national level of climate regimes. After all, our study shows that analyzing legitimacy debates is a worthwhile endeavor. 


\section{References}

No author (2009) One cheer for Copenhagen; An agreement makes some -- if not enough -headway. Cue the U.S. Senate. Washington Post, 20 December: A24.

No author (2014) Lima climate talks run into extra time with uncertain outcome. Times of India, 14 December.

No author (2014) Warming up for round one of the great Lima and Paris climate change blame game. The Australian, 12 December: 13.

Bernauer T, Mohrenberg S and Koubi V (2016) How relevant are input and output legitimacy in international environmental governance? National Centre of Competence in Research (NCCR) Challenges to Democracy in the $21^{\text {st }}$ Century Working Paper: 94.

Billett S (2010) Dividing climate change: global warming in the Indian mass media. Climatic Change 99(1-2): 1-16.

Boykoff MT and Boykoff JM (2004) Balance as bias: global warming and the US prestige press. Global Environmental Change 14: 125-136.

Brüggemann M, Silva-Schmidt F de, Hoppe I, Arlt D and Schmitt J B (2017) The appeasement effect of a United Nations climate summit on the German public. Nature Climate Change 7(11): 783-787.

Dalton R and Welzel C (2015) The Civic Culture Transformed: From Allegiant to Assertive Citizens. New York: Cambridge University Press.

Easton D (1965) A Systems Analysis of Political Life. Chicago, London: University of Chicago.

Ferree MM, Gamson WA, Gerhards J and Rucht D (2002) Shaping Abortion Discourse. Democracy and the Public Sphere in Germany and the United States. Cambridge: Cambridge University.

Franck TM (1990) The Power of Legitimacy among Nations. New York, NY, et al.: Oxford University. 
Fuchs D (2011) Cultural Diversity, European Identity and the Legitimacy of the EU. Cheltenham et.al.: Elgar.

Gerhards J, Offerhaus A and Roose J (2009) Wer ist verantwortlich? Die Europäische Union, ihre Nationalstaaten und die massenmediale Attribution von Verantwortung für Erfolge und Misserfolge. In: Marcinkowski F and Pfetsch B (eds) Politik in der Mediendemokratie. Wiesbaden: VS Verlag für Sozialwissenschaften, pp. 529-558.

Giddens A (2011) The Politics of Climate Change. Cambridge: Polity.

Gronau J, Nonhoff M, Nullmeier F and Schneider S (2009) Spiele ohne Brot? Leviathan 37(1): 117-143.

Habermas J (2003) On the Pragmatics of Communication. Oxford: Polity.

Harmeling S (2009) Global Climate Risk Index 2010. Who is most vulnerable? Weatherrelated loss events since 1990 and how Copenhagen needs to respond. Bonn: Germanwatch.

Hobolt SB and Tilley J (2014) Blaming Europe? Responsibility without Accountability in the European Union. Oxford et al.: Oxford University.

Hurrelmann A, Krell-Laluhová Z, Nullmeier F, Schneider S and Wiesner A (2009) Why the democratic nation-state is still legitimate: A study of media discourses. European Journal of Political Research 48(4): 483-515.

Hurrelmann, A, Gora, A and Wagner, A (2012) The legitimation of the European Union in the news media: three treaty reform debates. Journal of European Public Policy 20(4), 515534.

Jasanoff S (2011) Cosmopolitan knowledge: climate science and global civic epistemology. In J S Dryzek, R B Norgaard and D Schlossberg (eds) The Oxford Handbook of Climate Change and Society. Oxford: Oxford University Press. 
Karlsson-Vinkhuyzen S (2015) The legitimation of global energy governance: a normative exploration. In F Mancebo and I Sachs (eds) Transitions to Sustainability. Dordrecht: Springer Netherlands, pp. 119-130.

Karlsson-Vinkhuyzen S I, Friberg L and Saccenti E (2016) Read all about it! Public accountability, fragmented global climate governance and the media. Climate Policy: 112.

Konieczny E (2014) Gipfel, Krisen, Konferenzen: Die Entstehung diskursiver Macht in transnationalen Kommunikationsereignissen. Wiesbaden: Springer VS.

Kreye A (2004) Heitere Aussichten. Süddeutsche Zeitung, 18 December.

Kuyper J W, Linnér B-O and Schroeder H (2018) Non-state actors in hybrid global climate governance: Justice, legitimacy, and effectiveness in a post-Paris era. Wiley Interdisciplinary Reviews: Climate Change 9(1): e497.

Ladle R, Jepson P and Whittaker R (2005) Scientists and the media: the struggle for legitimacy in climate change and conservation science. Interdisciplinary Science Reviews 30(3): 231-240.

Lengauer G, Esser F and Berganza R (2012) Negativity in political news: A review of concepts, operationalizations and key findings. Journalism 13(2): 179-202.

Lück J, Wessler H, Maia R and Wozniak A (2018) Journalist-source relations and the deliberative system: A network performance approach to investigating journalism's contribution to facilitating public deliberation in a globalized world. International Communication Gazette 80(6): 509-531.

Mihm A (2014) Kritik an Einigung bei Klimakonferenz in Lima. Frankfurter Allgemeine Zeitung, 15 December: 1.

Moser SC (2010) Communicating climate change: History, challenges, process and future directions. Wiley Interdisciplinary Reviews: Climate Change 1(1): 31-53. 
Nisbet MC, Schäfer MS, Markowitz E, Thaker J, Ho SS and O’Neill S (eds) (2018) The Oxford Encyclopedia of Climate Change Communication. New York: Oxford University Press.

Nossek H and Kunelius R (2012) News flows, global journalism and climate summits. In E Eide and R Kunelius (eds) Media Meets Climate: The Global Challenge for Journalism. Göteborg: Nordicom, pp. 67-85.

O’Neill S, Williams, Hywel T. P., Kurz T, Wiersma B and Boykoff M (2015) Dominant frames in legacy and social media coverage of the IPCC Fifth Assessment Report. Nature Climate Change 5(4): 380-385.

Post S, Kleinen-von Königslöw K and Schäfer MS (2018). Between guilt and obligation: Debating the responsibility for climate change and climate politics in the media. Environmental Communication. Epub ahead of print 12 July 2018. DOI: 10.1080/17524032.2018.1446037.

Peatling S (2004) Global warming still leaves PM cold. Sidney Morning Herald,

Rother L (2004) U.S. waters down global commitment to curb greenhouse gases. New York Times, December 19, 16.

Schäfer MS (2015) Climate change in the media. In: Wright JD (ed.) International encyclopedia of the social \& behavioral sciences. Amsterdam: Elsevier, pp. 853-859.

Schäfer MS, Ivanova A and Schmidt A (2014) What drives media attention for climate change? Explaining issue attention in Australian, German and Indian print media from 1996 to 2010. International Communication Gazette 76(2): 152-176.

Schäfer MS and Schlichting I (2014) Media representations of climate change: A metaanalysis of the research field. Environmental Communication 8(2): 142-160.

Schäfer MS, Post S, Schwab R and Kleinen-von Königslöw K (2018). Transnationalisierte Öffentlichkeit und Klimapolitik. Publizistik 35(1), 10-29. 
Scharkow M (2011) Zur Verknüpfung manueller und automatischer Inhaltsanalyse durch maschinelles Lernen. Medien \& Kommunikationswissenschaft 59(4): 545-562.

Scharpf FW (1999) Demokratieprobleme in der europäischen Mehrebenenpolitik. In: Merkel W and Busch A (eds) Demokratie in Ost und West. Frankfurt/Main: Suhrkamp, pp. 672694.

Scharpf FW (2000) Interdependence and democratic legitimation. In: Pharr SJ and Putnam RD (eds) Disaffected Democracies: What's Troubling the Trilateral Countries? Princeton, NJ: Princeton Univ. Press, pp. 101-120.

Scharpf FW (2003) Problem-solving effectiveness and democratic accountability in the EU. Max Planck Institute for the Study of Societies: MPIfG Working Paper 03/1.

Schmidt A, Ivanova A and Schäfer MS (2013) Media attention for climate change around the world: A comparative analysis of newspaper coverage in 27 countries. Global Environmental Change 23(5): 1233-1248.

Schmidt A and Schäfer MS (2015) Constructions of climate justice in German, Indian and US media. Climatic Change 133(3): 535-549.

Schneider S, Hurrelmann A, Krell-Laluhová Z, Nullmeier F and Wiesner A (2010) Democracy's Deep Roots: Why the Nation State Remains Legitimate. New York: Palgrave Macmillan.

Shehata A and Hopmann D (2012) Framing climate change: A study of US and Swedish press coverage of global warming. Journalism Studies 13: 175-192.

Steffek J (2003) The Legitimation of international governance: A discourse approach. European Journal of International Relations 9(2): 249-275.

Wessler H, Wozniak A, Hofer L and Lück J (2016) Global multimodal news frames on climate change. The International Journal of Press/Politics 21(4): 423-445

Worlds of Journalism Study (2017). Journalistic roles. Aggregated data on key variables. Report. http://www.worldsofjournalism.org/data/data-and-key-tables-2012-2016/. 
Ylä-Anttila T and Luhtakallio E (2017) Justifications analysis: understanding moral evaluations in public debates. Sociological Research Online 21(4):1-15.

Zürn M (2004) Global governance and legitimacy problems. Government and Opposition 39(2): 260-287.

\footnotetext{
i From a different perspective (sociology of morality), but with a similar outcome Ylä-Anttila and Luhtakallio (2017) have looked at moral justifications used by political actors in media debates. Within the 'common good' as the basis of any moral justification in politics, they look for example at justifications recurring to civic worth or industrial worth which overlap strongly with the legitimation criteria of representation/participation and fairness (civic) or expertise and effectiveness (industrial) used here.

ii For Australia, we analyzed coverage in The Australian and the Sydney Morning Herald, for Brazil Folha de Sao Paulo and Estado do Sao Paulo, for Germany Frankfurter Allgemeine Zeitung and Süddeutsche Zeitung, for India the Times of India and the Hindu, for the US the New York Times and the Washington Post.

iii For each COP we analyzed one week before, the time period during the COP and one week after the COP. The concrete dates were as follows: COP 2004 in Buenos Aires: November 29 $9^{\text {th }}$ - December 24th. COP in 2009 in Copenhagen: November 30 $0^{\text {th }}$ - December 25th. COP 2014 in Lima: November 24 ${ }^{\text {th }}$ December 19th.

${ }^{\text {iv }}$ Some newspapers cannot be retrieved from Factiva or Lexis Nexis (e.g. the Frankfurter Allgemeine Zeitung in Germany). In such cases, we used the digital archives applying the search criteria described above.
} 